\title{
Use of amiodarone during pregnancy
}

\author{
David J. Robson ${ }^{1}$, M.V. Jeeva Raj ${ }^{2}$, Gerard C.A. Storey ${ }^{3}$ and David W. Holt ${ }^{3}$ \\ ${ }^{\prime}$ Greenwich District Hospital, London SE 10; ${ }^{2}$ Good Hope General Hospital, Sutton Coldfield, West Midlands; \\ ${ }^{3}$ Poisons Unit, Guy's Hospital, London SE1, UK.
}

\begin{abstract}
Summary: Two cases are reported in which amiodarone was administered during pregnancy for longer periods than has been reported previously. Limited placental transfer of amiodarone and its desethyl metabolite was observed in both cases. A normal child resulted from each pregnancy despite, in one case, amiodarone therapy throughout the entire pregnancy. However, caution is urged in the use of amiodarone during pregnancy in view of the limited data available.
\end{abstract}

\section{Introduction}

Amiodarone is used increasingly for the control of ventricular and supraventricular arrhythmias. The drug contains a high proportion of iodine $(75 \mathrm{mg}$ per $200 \mathrm{mg}$ ) and uncertainty as to the effect of this iodine load on the fetus has limited the use of amiodarone in pregnancy. Two recent reports (McKenna et al., 1983; Pitcher et al., 1983) have documented the use of amiodarone in the later stages of pregnancy without adverse effects to the fetus. We report two further cases, one involving a patient who conceived whilst receiving amiodarone and continued use of the drug throughout her pregnancy, the other a patient who received amiodarone for the final 17 weeks of her pregnancy.

\section{Case reports}

Case 1

A 31 year old woman presented in atrial fibrillation with signs of tight mitral stenosis. She subsequently underwent open mitral valvotomy and annuloplasty, following which she was in sinus rhythm; a month later she reverted into atrial fibrillation. Despite adequate control of heart rate with digoxin she became markedly limited by dyspnoea on exertion. She reverted to sinus rhythm following a D.C. shock. Before this, amiodarone had been started in a dose of $200 \mathrm{mg}$ tds. She continued on amiodarone $200 \mathrm{mg} / \mathrm{d}$, hydrochlorothiazide and amiloride (Moduretic), warfarin and an oral contraceptive. Although the return to

David J. Robson, M.B., M.R.C.P.; M.V. Jeeva Raj, M.B., F.R.C.P.; Gerard C. A. Storey, B.Sc. and David W. Holt, BSc., Ph.D.

Correspondence: D.W. Holt.

Accepted: 30 November 1983 sinus rhythm produced some symptomatic improvement, she was still markedly dyspnoeic on effort. Ultrasound studies suggested there was, again, significant mitral stenosis. The patient then discontinued her oral contraceptive and, despite being warned as to the risks of pregnancy, both with regard to herself and the fetus, she became pregnant. The pregnancy was reported and confirmed at seven weeks and warfarin was discontinued immediately.

It was considered essential to continue amiodarone to maintain sinus rhythm, as it was thought that a relapse into atrial fibrillation would produce marked haemodynamic deterioration. She was, therefore, maintained on amiodarone $200 \mathrm{mg} / \mathrm{d}$ for the remainder of her pregnancy. At six months the patient was admitted in acute pulmonary oedema. At this stage the mitral valve area on 2D ultrasound was $1 \mathrm{~cm}^{2}$. Despite these problems the pregnancy proceeded uneventfully, albeit using increasingly large doses of diuretics. At 37 weeks a healthy girl was delivered by Caesarian section. Immediately following delivery the mother went into acute pulmonary oedema and required ventilation for $24 \mathrm{~h}$. Subsequently, she made a satisfactory recovery and underwent mitral valve replacement. The child weighed $3.5 \mathrm{~kg}$ at birth and routine neonatal examination was normal in all respects; there was no goitre and no corneal changes were visible. Thyroid function tests measured at birth from cord blood were: thyroxine $209 \mathrm{nmol} / 1$, thyroid stimulating hormone (TSH) $3.2 \mu \mathrm{U} / \mathrm{ml}$; at one week thyroxine remained at $207 \mathrm{nmol} / \mathrm{l}$ but TSH was less than $1 \mu \mathrm{U} / \mathrm{ml}$. Table I shows amiodarone and desethylamiodarone concentrations in maternal plasma at intervals throughout the pregnancy and in maternal plasma, cord plasma, amniotic fluid and placenta at the time of delivery. These compounds were measured using high-performance liquid chromatographic techniques (Storey et al., 1982; Storey et al., 1983). At

(C) The Fellowship of Postgraduate Medicine, 1985 
Table 1 Amiodarone and desethylamiodarone concentrations in Case 1.

\begin{tabular}{lccc}
\hline Time & Sample & $\begin{array}{c}\text { Amiodarone } \\
(\mathrm{mg} / \mathrm{l})\end{array}$ & $\begin{array}{c}\text { Desethylamiodarone } \\
(\mathrm{mg} / \mathrm{l})\end{array}$ \\
\hline 3 months pre-partum & Maternal plasma & 0.7 & 0.8 \\
2 months pre-partum & Maternal plasma & 0.7 & 0.9 \\
1 month pre-partum & Maternal plasma & 0.5 & 0.7 \\
Birth & Maternal plasma & 0.5 & 0.8 \\
Birth & Cord plasma & 0.05 & 0.15 \\
Birth & Amniotic fluid & 0.02 & 0.11 \\
2 months post-partum & Maternal & 0.6 & 0.6 \\
& & 34 mg/kg wet weight \\
Birth & Placenta & 300
\end{tabular}

mitral valve replacement, two months later, concentrations of both compounds (amiodarone/desethylamiodarone) in myocardium and subcutaneous fat were $9 / 47$ and $197 / 43 \mathrm{mg} / \mathrm{kg}$ wet weight, respectively, whilst the patient was receiving $200 \mathrm{mg}$ amiodarone daily.

\section{Case 2}

A 27 year old primigravida was admitted to hospital at 22 weeks gestation with a $24 \mathrm{~h}$ history of rapid increase in pulse rate, vomiting and feeling faint. She had a 13 year history of intermittent palpitations, diagnosed one year previously as due to paroxysmal atrial tachycardia, for which she had received, successively, propranolol and metoprolol; on admission she was receiving metoprolol $50 \mathrm{mg}$ three times daily. On examination she had a sinus tachycardia, rate 150 beats/min, which was not controlled by either additional doses of metoprolol or intravenous verapamil. Therapy with oral amiodarone was started, $200 \mathrm{mg}$ four times daily for one week. She was discharged two weeks later with a heart rate of 100 beats/min, receiving amiodarone $200 \mathrm{mg}$ twice daily and metoprolol $25 \mathrm{mg}$ twice daily.

She was re-admitted two months later complaining of palpitations, tiredness and nausea; her heart rate was 130 beats/min. Amiodarone dose was increased to
$200 \mathrm{mg}$ three times daily, metoprolol was stopped and frusemide, $40 \mathrm{mg}$ twice daily, was added to her medica- $\rightarrow$ tion for the treatment of pulmonary oedema. During the following three weeks of hospital care her pulmon-.ary oedema resolved but her palpitations persisted. or Her heart rate was in the range $100-130$ beats $/ \mathrm{min}$, 을 whilst measurements of fetal heart rate were in the range $100-120$ beats $/ \mathrm{min}$.

In the 39th week of pregnancy she went into spontaneous labour followed by elective Anderson forceps delivery of a healthy boy weighing $2.9 \mathrm{~kg} ;$ Apgar scores were 9 and 10 at 1 and 5 minut $8, \infty$ respectively. Neonatal examinations were all norma or

Blood samples were collected from the mother during the pregnancy and at delivery for the measurement of amiodarone and desethyl- $\frac{\partial}{0}$ amiodarone, together with a sample of placenta. The results are summarized in Table II.

\section{Discussion}

In both cases maternal plasma concentrations of amiodarone and desethylamiodarone were consistent 3 with chronic therapy on the prescribed dose through- out the pregnancy (Holt and Storey, 1983) and cord 3 . blood concentrations at delivery show a degree of $\delta$ transplacental passage of the two compounds similar

Table II Amiodarone and desethylamiodarone concentrations in Case 2

\begin{tabular}{|c|c|c|c|}
\hline Time & Sample & $\begin{array}{c}\text { Amiodarone } \\
(\mathrm{mg} / \mathrm{l})\end{array}$ & $\begin{array}{c}\text { Desethylamiodarone } \\
(\mathrm{mg} / \mathrm{l})\end{array}$ \\
\hline $\begin{array}{l}1 \text { month pre-partum } \\
\text { Birth } \\
\text { Birth }\end{array}$ & $\begin{array}{l}\text { Maternal plasma } \\
\text { Maternal plasma } \\
\text { Cord plasma }\end{array}$ & $\begin{array}{l}1.5 \\
1.1 \\
0.16\end{array}$ & $\begin{array}{l}1.6 \\
1.2 \\
0.26\end{array}$ \\
\hline Birth & Placenta & $72^{(m g / k}$ & $\begin{array}{r}\text { wet weight) } \\
492\end{array}$ \\
\hline
\end{tabular}


to that previously reported (McKenna et al., 1983; Pitcher et al., 1983). There are no data on placental concentrations of amiodarone and desethylamiodarone for comparison with these cases but both contained comparatively high concentrations of desethylamiodarone (Holt et al., 1984); tissue samples obtained in Case 1 at mitral valve replacement contained concentrations of both compounds of the same order as those previously found (Storey et al., 1983).

Previous reports have documented the use of amiodarone during only the final seven (McKenna et

\section{References}

HOLT, D.W. \& STOREY, G.C.A. (1983). In Amiodarone and Arrhythmias p. 11, Pergamon Press, Oxford.

HOLT, D.W., ADAMS, P.C., CAMPBELL, R.W.F., MORLEY, A.R., CALlaGHAN, J. \& STOREY G.C.A. (1984). Amiodarone and its desethyl metabolite: tissue distribution and ultrastructural changes in amiodarone-treated patients. British Journal of Clinical Pharmacology, 17, $195 P$.

MCKENNA, W.J., HARRIS, L., ROWLAND, E., WHITELAW, A., STOREY, G.C.A. \& HOLT, D.W. (1983). Amiodarone therapy during pregnancy. American Journal of Cardiology, 51, 1231. al., 1983) and three (Pitcher et al., 1983) weeks of pregnancy. One of our patients (Case 1) continued amiodarone throughout the pregnancy and, to our knowledge, this is the first documented case in which this has occurred; the other patient was exposed to the drug for the final 17 weeks of her pregnancy. Although the fetus was exposed to the potential teratogenic effects of amiodarone, a normal child resulted in each case. However, despite this successful outcome, there is no reason for other than continued caution in the use of amiodarone during pregnancy.

PITCHER, D., LEATHER, M.H., STOREY, G.C.A. \& HOLT, D.W. (1983). Amiodarone in pregnancy. Lancet, i, 597.

STOREY, G.C.A., HOLT, D.W., HOLT, P. \& CURRY, P.V.L.C. (1982). High-performance liquid chromatographic measurement of amiodarone and its desethyl metabolite methodology and preliminary observations. Therapeutic Drug Monitoring, 4, 385.

STOREY, G.C.A., ADAMS, P.C., CAMPBELL, R.W.F \& HOLT, D.W. (1983). High-performance liquid chromatographic measurement of amiodarone and desethylamiodarone in small tissue samples after enzymatic digestion. Journal of Clinical Pathology,36, 785. 